ORIGINAL ARTICLE

\title{
ULTRASONIC EVALUATION OF MEDIAN NERVE BEFORE AND AFTER CARPAL TUNNEL DECOMPRESSION
}

\author{
Sami Hasanin Mohammad, Hosni Hassan Salama, *Mansour Abdelmagid Makia, \\ Hamad Abdulsayed Hamad \\ Neurosurgery Department, Faculty of Medicine, Zagazig University, Zagazig, Egypt
}

\author{
*Corresponding author: \\ Hamad Abdulsayed \\ Hamad \\ Neurosurgery Department, \\ Faculty of Medicine, \\ Zagazig University,Zagazig, \\ Egypt \\ e-mail: \\ hswideg@yahoo.com
}

$\begin{array}{ll}\text { Submit Date } & 2019-04-02 \\ \text { Revise Date } & 2019-05-22 \\ \text { Accept Date } & 2019-05-27\end{array}$

\section{ABSTRACT}

Background: Carpal tunnel syndrome (CTS) is the most frequent peripheral compression neuropathy of the median nerve in the wrist. Highdefinition ultrasonography can detect and follow up any postoperative complications causing persistent complaint or poor result like hematoma, scarring, nerve damage or incomplete cutting of retinaculum. The aim of the study was to evaluate effect of surgical decompression on cross sectional area (CSA) of median nerve in patients with carpal tunnel syndrome and examine the role of ultrasound as a follow up tool. Methods: The prospective observational study was done on 20 patients with CTS referred for peripheral neurosurgery. All patients were subjected to full history taking, complete general medical examination, electromyelography (EMG), high-definition ultrasonography including cross-sectional area before and after surgical decompression (open fashion or endoscopically). Results: Using EMG, there is statistically significant decrease in distal motor latency (DML) while there is significant improvement in amplitude following surgical decompression $(\mathrm{p}<0.001)$. On using US, there is statistically significant increase in anteroposterior diameter (APD) wrist and decrease in CSA at wrist. There is significant negative correlation between preoperative DML and APD at wrist. There is significantly negative correlated with postoperative DML and pre and postoperative APD at wrist. On the other hand, there is significantly positive correlation with postoperative DML and pre CSA. Conclusions: There is a decrease in size of the median nerve after surgical decompression denoting that the preoperative increase in median nerve CSA at the carpal tunnel is partially reversible. Ultrasonographic parameters correlated with EMG ones so it can be used as an alternative tool for postoperative follow up.

Keywords: Tunnel; Syndrome; Nerve; Ultrasound

\section{INTRODUCTION}

arpal tunnel syndrome is the most
common entrapment neuropathy in the
body caused by pressure on the median nerve
in front of the wrist. It commonly affects
middle age females, and usually touches the
dominant hand. The condition occurs when
there is imbalance between the space and its
contents; hence the pressure is applied to the
median nerve itself [1].
Diagnosis is usually clinically combined with
Nerve Conductive Studies (NCS). Magnetic
Resonance Imaging (MRI) and Ultrasound
(US) are choices for subsequent investigation.
US is well established as a diagnostic tool in
CTS. It is readily available non-invasive tool which has a shorter examination time. It can be used to measure a number of median nerve parameters including size, vascularity (using power Doppler) and mobility (using dynamic imaging). In addition, US provides information on anatomical variations of the median nerve and surrounding structures that may be a causative factor in CTS [2].

This study is designed to evaluate the effect of surgical decompression on cross sectional area of median nerve in patients with carpal tunnel syndrome and examine the role of ultrasound as a follow up tool. 


\section{METHODS}

This prospective observational study was conducted in the Neurosurgery Department, Zagazig University Hospitals.

\section{Study population}

The study included 20 patients with CTS who were referred for peripheral neurosurgery.

\section{Inclusion criteria:}

The patients who were suspected to have CTS and both genders aged more than 18 years old were included.

\section{Exclusion criteria:}

Patients with rheumatoid arthritis, amyloidosis, thyroid diseases or on hemodialysis, patients with traumatic injuries to the upper extremities,patients with surgical revision of a previous carpal tunnel syndrome and US showing bifid median nerve or lesion causing external compression on the nerve were excluded.

All patients were subjected to: Full history taking including pain, numbness and weakness with duration, complete general medical examination including Phalen's test and Tinel's sign, electromyelography (EMG) including distal motor latency (DML) of median nerve, High-definition ultrasonography including measuring cross sectional area, routine laboratory investigations for preparation of surgery, surgical decompression performed either in open fashion or endoscopically and postoperatively, distal motor latency (DML) of median nerve and cross sectional area were measured again.

\section{High-definition ultrasonography}

technique: A real-time scanner with a 19$\mathrm{MHz}$ rectilinear array transducer was utilized. Patients sat down in a chair with their arms extended and hands resting in a horizontal supinated position. The largest CSA of the median nerve was assessed at 2 positions: distal to the carpal tunnel inlet between the pisiform bone and the scaphoid tubercle (i.e. the distal wrist flection crease) (rascetta); and in the forearm $5 \mathrm{~cm}$ proximal to the mentioned line, using manual tracing in serial transverse scans.

Transverse scans were only used to localize the median nerve and exclude relevant pathologies other than CTS. The largest CSA was determined by visual inspection during transverse scanning. In case of uncertainty, several transverse measurements were taken until the largest CSA was identified. Assessments of the largest CSA were performed twice and the arithmetic means of the 2 assessments were recorded. Examinations before and after treatment were performed in the same standardized manner.

Ethical consideration: a written informed consent was obtained from all participants and the study was approved by the research ethical committee of Faculty of Medicine, Zagazig University. The work has been carried out in accordance with The Code of Ethics of the World Medical Association (Declaration of Helsinki) for studies involving humans.

\section{Statistical analysis}

Data were then imported into Statistical Package for the Social Sciences (SPSS version 20.0) software for analysis. Qualitative data was represented as frequency and percentage. Quantitative data was represented by mean $\pm \mathrm{SD}$. Chi square test was used to measure the association of qualitative variable. Paired t test was used to evaluate change of EMG and US results pre and postoperatively. Pearson's correlation was used to measure correlation between two continuous variables. $P$ value was set at $<0.05$ for significant results $\& \leq 0.001$ for highly significant result.

\section{RESULTS}

Mean age of the studied groups was $45.55 \pm 8.23$ with minimum 32 and maximum 60 years old (table 1 ). Females constituted the majority of the studied patients (figure 1).

Eighty five percent of the studied patients had positive Tinel's test and $80 \%$ were positive as regard carpal compression test and all of them had positive phalen's test (Table 2). Half of the studied patients reported scar tenderness (figure 2)

Using EMG, there is statistically significant decrease in DML after surgery while there is significant improvement in amplitude following surgical decompression (table 3). Regarding US parameters, there is statistically significant increase in APD wrist and decrease in wrist CSA (table 3). 
There is significant negative correlation between preoperative DML and APD at wrist (table 4)

There is significantly negative correlation between postoperative DML and pre and postoperative APD at wrist. On the other hand, there is significantly positive correlation with postoperative DML and pre CSA (table 5)

Table 1. Distribution of the studied patients according to age (years):

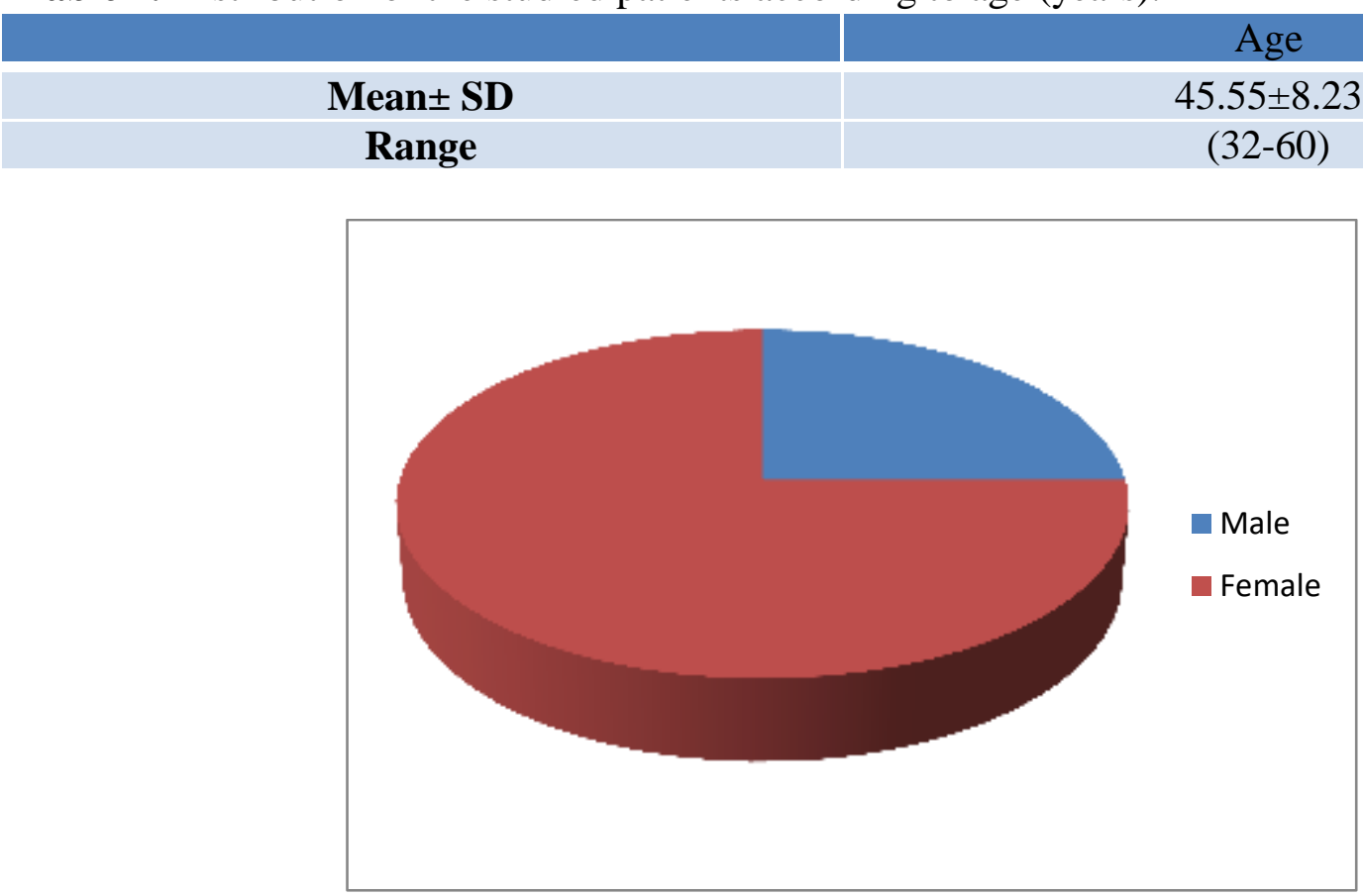

Figure 1. Distribution of the studied patients according to gender

Table 2. Distribution of the studied patients regarding diagnostic tests:

\begin{tabular}{|c|c|c|c|}
\hline Tinel's test & & $\mathrm{N}(20)$ & $\%$ \\
\hline & $-\mathbf{V E}$ & 3 & 15.0 \\
\hline Phalen's test & $\mathbf{+ V E}$ & 17 & 85.0 \\
\hline & $-\mathbf{V E}$ & 0 & 0.00 \\
\hline Carpal compression test & $\mathbf{+ V E}$ & 20 & 100.0 \\
\hline & $\mathbf{- V E}$ & 4 & 20.0 \\
\hline & $\mathbf{+ V E}$ & 16 & 80.0 \\
\hline
\end{tabular}




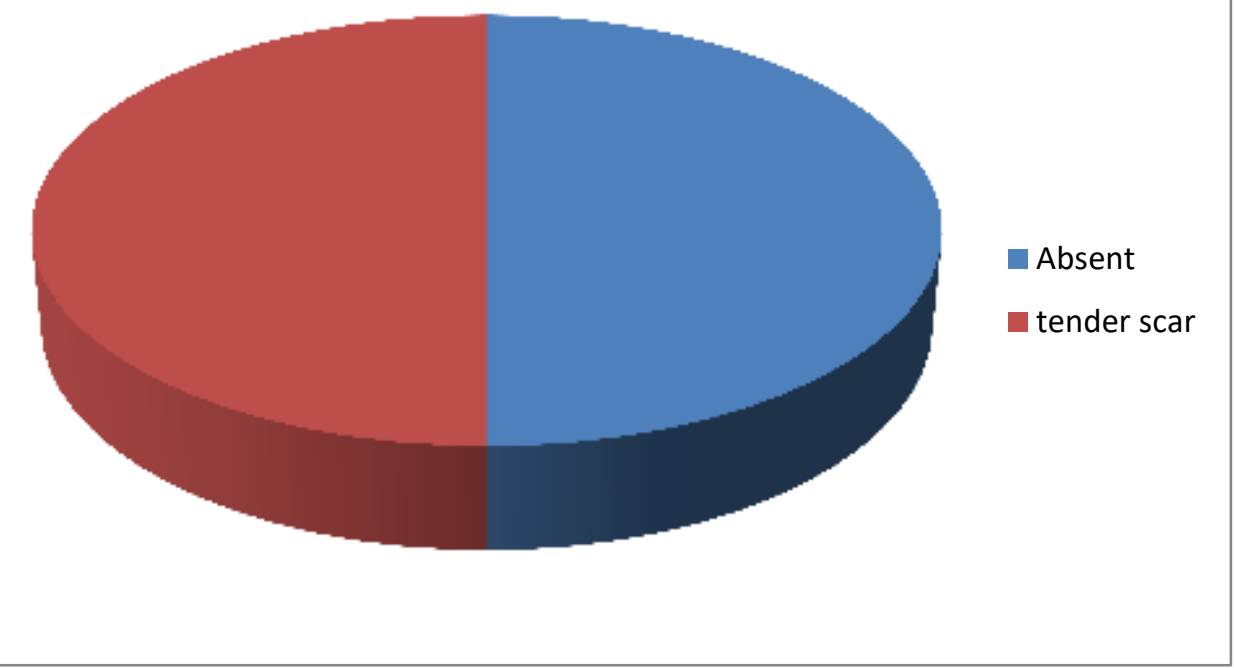

Figure 2. pie chart showing distribution of the studied patients regarding scar pain 
Table 3. Change assessment in EMG and US before and after surgery in the studied patients:

\begin{tabular}{|c|c|c|c|c|c|}
\hline & & Preoperative & Postoperative & Paired t & $\mathrm{P}$ \\
\hline \multirow{2}{*}{$\sum_{[=1}^{b}$} & DML (msc) & $5.67 \pm 1.21$ & $4.3 \pm 0.51$ & 6.492 & $<0.001$ \\
\hline & $\mathbf{A M P}(\mathrm{uV})$ & $5.87 \pm 2.08$ & $7.75 \pm 2.28$ & -6.726 & $<0.001$ \\
\hline \multirow{2}{*}{$\mathscr{D}$} & APD Wrist (mm) & $1.81 \pm 0.18$ & $2.03 \pm 0.13$ & -8.459 & $<0.001$ \\
\hline & CSA Wrist $\left(\mathrm{mm}^{2}\right)$ & $17.2 \pm 5.36$ & $8.35 \pm 0.81$ & 7.366 & $<0.001$ \\
\hline
\end{tabular}

mm: millimeter $\quad \mathrm{uV}$ : microvolt $\quad$ EMG: electromyography US: ultasonography, DML: distal motor latency, AMP: amplititude, APD: anteroposterior diameter, CSA cross sectional area

Table 4 correlation between EMG results before surgery and US findings in the studied patients:

\begin{tabular}{|c|c|c|c|}
\hline & & $\begin{array}{c}\text { Preoperative EMG- } \\
\text { DML }\end{array}$ & $\begin{array}{c}\text { Preoperative EMG- } \\
\text { AMP }\end{array}$ \\
\hline \multirow[t]{2}{*}{ Preoperative APD-Wrist } & $\mathbf{r}$ & $-0.495^{*}$ & 0.120 \\
\hline & $\mathbf{P}$ & 0.026 & 0.615 \\
\hline \multirow[t]{2}{*}{ Preoperative CSA-US } & $\mathbf{r}$ & 0.881 & -0.451 \\
\hline & $\mathbf{P}$ & 0.001 & .046 \\
\hline \multirow[t]{2}{*}{ Postoperative APD-Wrist } & $\mathbf{r}$ & -0.453 & -0.004 \\
\hline & $\mathbf{P}$ & 0.045 & 0.987 \\
\hline \multirow[t]{2}{*}{ Postoperative CSA-US } & $\mathbf{r}$ & 0.182 & 0.140 \\
\hline & $\mathbf{P}$ & 0.443 & 0.555 \\
\hline
\end{tabular}

EMG: electromyography US: ultasonography, DML: distal motor latency, AMP: amplititude, APD: anteroposterior diameter, CSA cross sectional area 
Table 5. correlation between EMG results after surgery and US findings in the studied patients:

\begin{tabular}{|c|c|c|c|}
\hline & & Postoperative EMG-DML & Postoperative EMG-AMP \\
\hline \multirow{2}{*}{$\begin{array}{c}\text { Preoperative APD- } \\
\text { Wrist }\end{array}$} & $\mathbf{r}$ & -0.721 & 0.096 \\
\hline & $\mathbf{P}$ & $<0.001$ & 0.686 \\
\hline \multirow{2}{*}{$\begin{array}{c}\text { Preoperative CSA- } \\
\text { US }\end{array}$} & $\mathbf{r}$ & 0.616 & -0.286 \\
\hline & $\mathbf{P}$ & 0.004 & 0.222 \\
\hline \multirow{2}{*}{$\begin{array}{l}\text { Postoperative APD- } \\
\text { Wrist }\end{array}$} & $\mathbf{r}$ & -0.627 & 0.048 \\
\hline & $\mathbf{P}$ & 0.003 & 0.840 \\
\hline \multirow{2}{*}{$\begin{array}{c}\text { Postoperative CSA- } \\
\text { US }\end{array}$} & $\mathbf{r}$ & 0.203 & 0.146 \\
\hline & $\mathbf{P}$ & 0.391 & 0.540 \\
\hline
\end{tabular}

EMG: electromyography US: ultasonography, DML: distal motor latency, AMP: amplititude, APD: anteroposterior diameter, CSA cross sectional area 

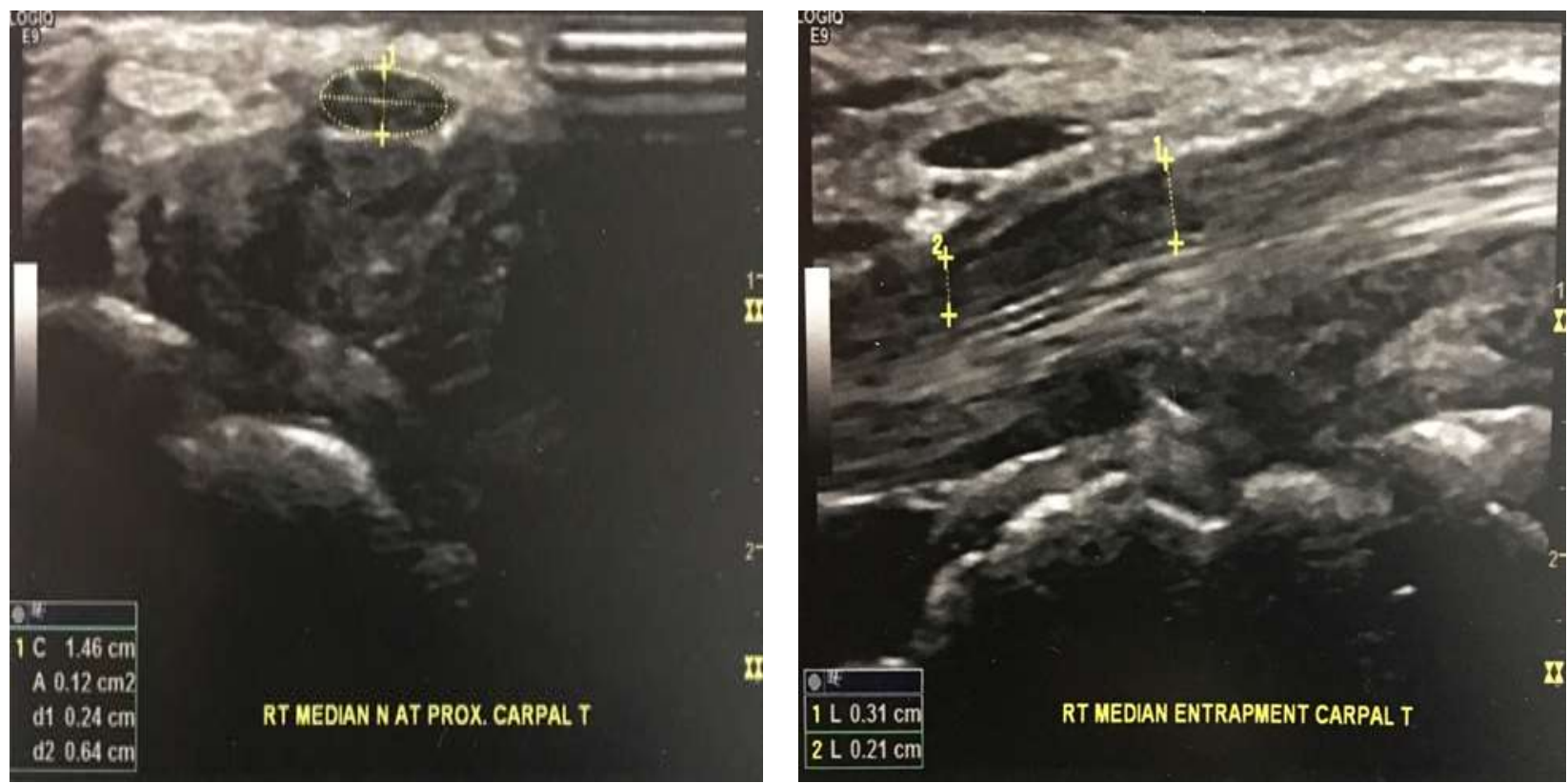

\section{Pre-operative USS}

Figure (3) USS show flattening of right median nerve with hypo-echoic texture loss of nerve fascicles, CSA at wrist was $12 \mathrm{~mm} 2$ by tracing method and AP diameter was $21 \mathrm{~mm}$ at wrist $31 \mathrm{~mm}$ at forearm, all these are confirm the suspected diagnosis of idiopathic CTS

\section{Follow up USS :}

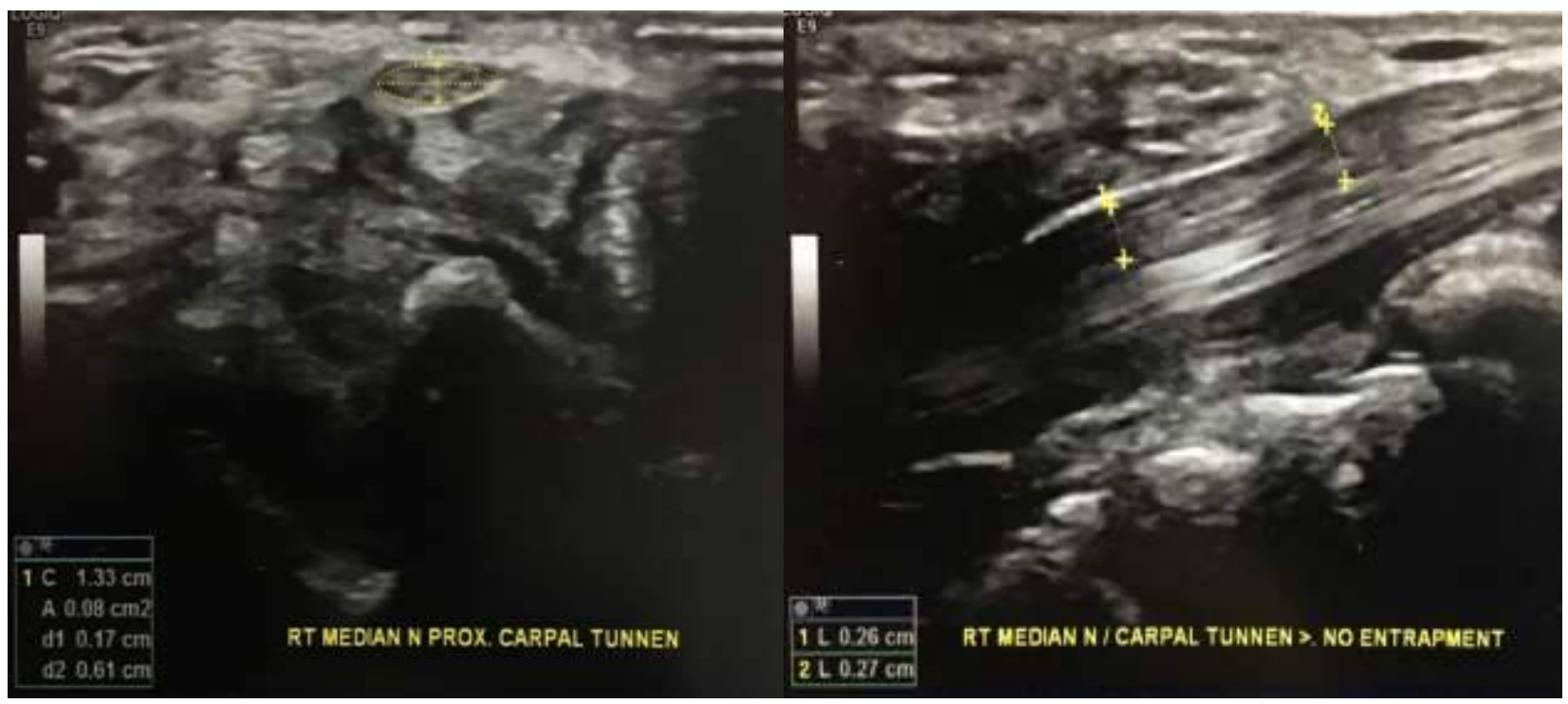

\section{Post-operative USS}

(Figure 2) USS showing decrease CSA to normal value, AP at wrist significantly increased and AP forearm significantly decrease to be equalized diameter along it course from lower third forearm to proximal carpal canal, indicating improvement of nerve morphology in correlation with physiology as the following pictures show .

\section{DISCUSSION}

Carpal Tunnel syndrome causes an increase in CSA of the median nerve. Such changes can be assessed by high-definition 
ultrasonography. The compression in the carpal tunnel leads to venous stasis and edema of nerve axons proximal to the compression site, which in turn results in swelling of the nerve and an increase in CSA and mechanical compression appear as decrease in Anterior Posterior diameter [3].

High-definition ultrasonography can thus be used for diagnosis of CTS with an accuracy that is equal to electrodiagnostic studies, it may give further information about an underlying pathological entity such as a ganglion cyst, or it may provide information about muscular atrophy [4].

The largest percentage of the studied patients was female which agreed with the fact that CTS is commoner among females. Patients' age ranged from 32 to 60 years old. These findings were in harmony with a previous study where age of affection was close to our findings [5]. Half of our studied patients had postoperative scar tenderness as opposed to a previous study by Tas et al. [6] whose largest majority of patients had postoperative tenderness.

In the current study, a significant improvement in EMG was noted as patients had significantly an increase in amplitude and significantly decreased in DML. Also, a significant increase in APD and decrease in CSA were also observed.

Tas et al. [6] detected a statistically significant decline of the mean CSA of the median nerve proximally along with 3 months after surgical decompression. Additionally, DML was also enhanced significantly after surgical decompression. Even though all patients improved clinically, one fifth of them did not have a lessening in the CSA. While $98 \%$ of patients who were obtainable for electrodiagnostic follow up exhibited an upgrading of the DML, only $80 \%$ had a reduction in the CSA.

There is significant negative correlation between preoperative DML and APD at wrist. There is significantly negative correlation between postoperative DML and pre and postoperative APD at wrist. On the other hand, there is significantly positive correlation with postoperative DML and pre CSA.
Smid and Visser [7] did not find any significant correlation between time of follow up and reduction in CSA size, which could indicate that after 3 months, the CSA will not show any further decrease. Vogelin et al. [5] found a statistically significant correlation between CSA and clinical improveqment.

Tas et al. [3] found that the reduction of CSA was not statistically significantly correlated with the amount of reduction of the DML.

Wanitwattanarumlug et al. [6] examined CTS patients and asymptomatic control subjects regarding ultrasound and nerve conduction studies. They found no difference of the US cutoff values of the median nerve. The mean CSA of medial nerve was also not different in the healthy population when compared to the others.

Fowler et al. [9] examined whether ultrasound can be depended upon as a first-line diagnostic test which is more cost-effective than using EDX alone. They concluded that the use of diagnostic ultrasound as a first-line for confirmation of a clinical diagnosis of CTS is a cost-effective strategy in the hands of a specialist. Although first-line ultrasound was associated with improved false-negative rates over the use of EDX alone in the general practitioner model, it resulted in a substantial increase in charges over the use of EDX alone. They suggested that ultrasound is a cost-effective option for confirming the clinical diagnosis of carpal tunnel syndrome in the specialist's office.

Tas et al. [6] studied the history of median nerve morphology at the carpal tunnel after surgical decompression assessed by highdefinition ultrasonography. They reported a decrease in size of the median nerve after surgical decompression, suggesting that the preoperative increase in median nerve CSA at the carpal tunnel may be due to compression and that enlargement of the median nerve is (partially) reversible.

Moran et al. [8] determined the usefulness of sonography measurements of the CSA of the median nerve in the diagnosis of CTS and in grading its severity. They concluded that measurement of median nerve CSA at the tunnel inlet by sonography is a useful tool for initial diagnosis in patients with clinical suspicion of CTS. 


\section{CONCLUSION}

There is a decrease in size of the median nerve after surgical decompression, signifying that the preoperative upsurge in median nerve CSA at the carpal tunnel is attributed to compression and that enlargement of the median nerve is, to some extent, reversible. Also, ultrasonographic result correlated with EMG parameters so it can be used as an alternative tool for postoperative follow up.

\section{Declaration of interest}

The authors report no conflicts of interest. The authors alone are responsible for the content and writing of the paper.

Funding information:None declared

\section{REFERENCES}

1- Chow, J.C. Carpal tunnel syndrome. In: The Wrist. Edited by Watson $\mathrm{KH}$ and Weinzweig $\mathrm{J}, 1^{\text {st }}$ ed. Ch.9. Philadelphia, New York, London; (2001) 107.

2- Aroori S, Spence R Carpal tunnel syndrome. Ulster Med. J. (2008); 77(1): 6-17.

3- Simon NG, Ralph JW, Lomen-Hoerth C, Poncelet AN., Vucic S., Kiernan MC, et al. Quantitative ultrasound of denervated hand muscles. Muscle Nerve; (2015) 52: 221- 30.

4- Vögelin E, Mészàros $T$, Schöni $F$, and Constantinescu measurements and detection of anatomical features in carpal tunnel syndrome. Scientific World Journal; (2014) 657906.

5- Wanitwattanarumlug $B$, Varavithya $\mathrm{V}$ and Aramrussameekul W Evaluating the crosssectional area (CSA) of the median nerve by ultrasound in carpal tunnel syndrome (CTS). Journal of Medicine and Medical Science; (2011) 2(7): 961-965.

6- Tas, S., Staub, F., Dombert, T., Marquardt G, Senft C, Seifert V, et al. Sonographic shortterm follow-up after surgical decompression of the median nerve at the carpal tunnel: a single center prospective observational study. Neurosurg Focus; (2015) 39: 1-5.

7- Smid MH, Visser LH Carpal tunnel syndrome: clinical and sonographic follow-up after surgery. Muscle Nerve; (2008) 38: 987-991.

8- Moran L, Perez M, Esteban A., Bellon J., Arranz B., and del Cerro M. Sonographic measurement of cross-sectional area of the median nerve in the diagnosis of carpal tunnel syndrome: correlation with nerve conduction studies. J Clin Ultrasound; (2009) 37: 125-31.

9- Fowler JR, Maltenfort MG and Ilyas AM Ultrasound as a first-line test in the diagnosis of carpal tunnel syndrome: A cost-effectiveness analysis. Clin Orthop Relat Res; (2013) 471: 932937.

To Cite This Article: Sami HM, Hosni HS, * Mansour AM, Hamad AH . Ultrasonic Evaluation of Median Nerve
before and after Carpal Tunnel Decompression.ZUMJ 2019;25(6);878-886.DOi:
10.21608/zumj.2019.10604.11120.

